\title{
Design of High-Power Energy Storage Bidirectional Power Conversion System
}

\author{
Chen, Xuhai; Chen, Yanlian; Lin, Zhenghuang; Mao, Xingkui; Chen, Jiaqiao; Zhang, Zhe
}

Published in:

Proceedings of 24th International Conference Electronics

Link to article, DOI:

10.1109/IEEECONF49502.2020.9141627

Publication date:

2020

Document Version

Peer reviewed version

Link back to DTU Orbit

Citation (APA):

Chen, X., Chen, Y., Lin, Z., Mao, X., Chen, J., \& Zhang, Z. (2020). Design of High-Power Energy Storage Bidirectional Power Conversion System. In Proceedings of 24th International Conference Electronics IEEE. https://doi.org/10.1109/IEEECONF49502.2020.9141627

\section{General rights}

Copyright and moral rights for the publications made accessible in the public portal are retained by the authors and/or other copyright owners and it is a condition of accessing publications that users recognise and abide by the legal requirements associated with these rights.

- Users may download and print one copy of any publication from the public portal for the purpose of private study or research.

- You may not further distribute the material or use it for any profit-making activity or commercial gain

- You may freely distribute the URL identifying the publication in the public portal 


\title{
Design of High-Power Energy Storage Bidirectional Power Conversion System
}

\author{
Xuhai Chen ${ }^{1}$, Yanlian Chen ${ }^{2,}$, Zhenghuang Lin ${ }^{2}$, Xingkui Mao ${ }^{2}$, Jiaqiao Chen ${ }^{1}$, Zhe Zhang ${ }^{3}$ \\ ${ }^{I}$ Fujian Electric Power Survey \& Design Institute, \\ Fuzhou, China \\ ${ }^{2}$ College of Electrical Engineering and Automation, Fuzhou University, \\ Fuzhou, China \\ ${ }^{3}$ Department of Electrical Engineering, Technical University of Denmark, \\ Kgs. Lyngby, Denmark \\ petereisenhower@hotmail.com
}

\begin{abstract}
Aiming at problems of the energy storage PCS (power conversion system) with more applications and complicated working conditions, it is difficult to cover all applications with a single control scheme. This paper analyzes and designs the energy storage PCS in the state of grid-tied and islanding operation modes. Control schemes are designed for PCS working in different applications. The output current control in synchronous rotating coordinate system is adopted during grid-tied operation. The droop control is used during stand-alone parallel operation. In order to verify the design and control, a $500 \mathrm{~kW}$ PCS prototype was built and tested. The experiments show that the prototype has good performance and high working stability, including output current or voltage THD, efficiency, steady state, transition between grid-tied and stand-alone mode etc. The output current control and droop control adopted by the system can meet the requirements under different working conditions.
\end{abstract}

Index Terms-Energy storage; Power conversion system; Bidirectional power flow; Droop control; Parallel operation.

\section{INTRODUCTION}

The development of renewable energy and the unremitting pursuit of building strong power grids have promoted the developments of energy storage technologies. According to the data of National Statistics Bureau of China, the proportion of the generation capacity of wind power and photovoltaic power in China is far larger than that of the power generation in 2018; there are large renewable energy generation capacity to be abandoned. This is due to the unpredictable and fluctuated power generation of renewable energy and the insufficient capability of the power grid. The energy storage technology can be used to suppress the output fluctuations of wind and solar energy, and to improve the power grid capability of absorbing the new energy. Resultantly, the utilization of renewable energies is increased [1], [2], and the stability of the grid is improved. Moreover, the energy storage will also supply additional service to the grid, such as balancing peak-valley shifting. The application of the energy

Manuscript received 4 February, 2020; accepted 11 April, 2020. storage system in the load or consumer side will get more profits to grow rapidly. The research of energy storage PCS has become a focusing research topic.

The energy storage system is usually constructed with key energy storage units and power conversion system. The key storage units have great impact on the system cost and size, and mainly include superconducting energy storage [3], flywheel energy storage and electrochemical energy storage, etc. [4], [5]. Among them, electrochemical energy storage, such as lithium batteries, has the highest energy density. The electrochemical energy storage has been used intensively although it has relatively high cost. However, with large scale of utilization, the cost of implementing power lithium batteries are constantly reducing in recent years.

The power conversion system or bidirectional power converter is the interface between the energy storage units and the grids or load consumers. The system not only converts DC storage energy to the loads or the grids bidirectionally, but also supplies high quality power, such as low total harmonic distortion (THD) current to the girds or the load consumers, or low ripple charging current to the energy storage units. It has great effect on the energy system working stability and power quality, and will be challenged by complicated operations, such as charge and discharge modes when the grid fails or under maintenance. It must be switched between grid-tied and stand-alone modes to ensure the power supply of local critical load.

In [6], [7], the multi-level current source inverter is implemented grid-tied operation. However, the current source inverter cannot supply power for the local loads when the inverter works in stand-alone mode. In [8], the control combining the droop control and the virtual synchronous generator is proposed to achieve accurate tracking of active power reference under grid-tied mode and stand-alone mode, but the control parameter design is complicated. The PCS output current control in the synchronous rotating coordinate system can achieve grid-tied operation and ensure the high quality output current. However, it is difficult to ensure supply the local load in the stand-alone mode with the current control [9]-[10]. Adding a voltage loop can solve this problem, but it can't solve the circulation current in multiple 
PCS parallel operation when PCS works in stand-alone mode, while the droop control can solve the circulating current under stand-alone operation [11]-[15].

In order to design PCS with capabilities of high quality, high power and parallel connection operation to meet the large-scale energy storage system, the hybrid control scheme is proposed in this paper. This paper is structured as follows. After this introduction, Section II presents the PCS main circuit topology with the T-type three-level topology and its modelling. Section III presents the proposed hybrid control scheme. Section IV describes the high-power PCS key parameters design. Section V presents a prototype with rated power of $500 \mathrm{~kW}$, which is able to adapt to different operation modes. Finally, the conclusion is given in Section VI.

\section{MAIN TOPOLOGY PRINCIPLE AND MODELLING}

This paper uses the T-type three-level topology for high-power PCS shown in Fig. 1, which has advantages of small size and high output current quality. Comparing with the I-type three-level topology using diode clamp, the number of diodes of the T-type converter are reduced.

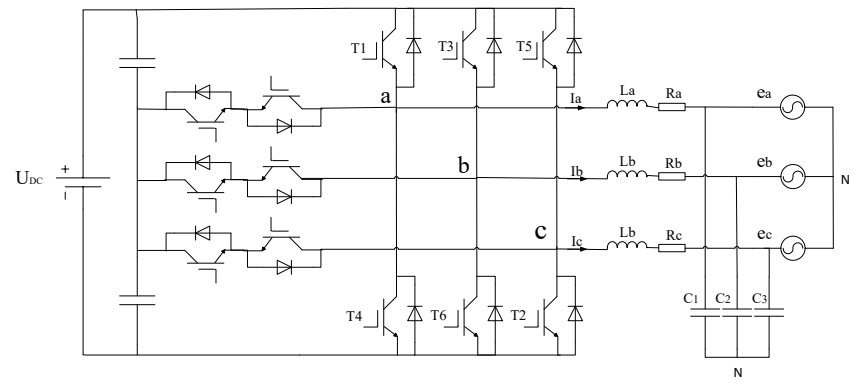

Fig. 1. Topology of the PCS main circuit.

Figure 2 is a single-phase equivalent circuit of a T-type three-level topology, the operation state of the three-level topology is more complicated than the two-level topology. It can be divided into six operation states according to the current flow direction.

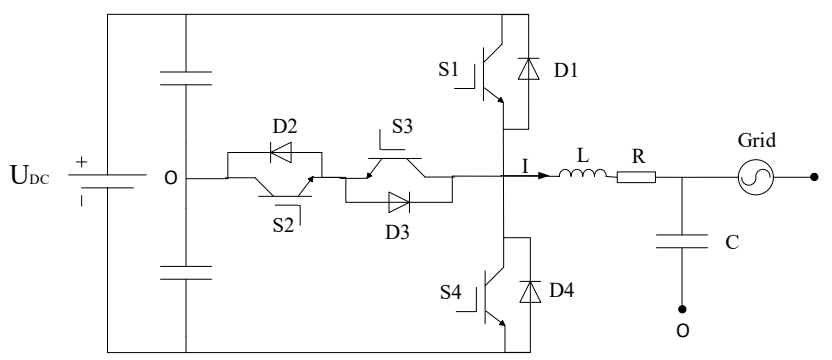

Fig. 2. Single-phase equivalent circuit diagram.

P1 state: S1 is turned on, S2, S3 and S4 are turned off, and the current flows from the converter DC side to the grid through $\mathrm{S} 1$, and the output voltage is $+0.5 \mathrm{U}_{\mathrm{dc}}$.

P2 state: S1 is turned on, S2, S3 and S4 are turned off, and the current flows from the grid to the converter DC side through D1, and the output voltage is $+0.5 \mathrm{U}_{\mathrm{dc}}$.

$\mathrm{O} 1$ state: S2 and S3 are on, S1 and S4 are off, and the current passes the midpoint $\mathrm{O}$ of DC voltage side through D3 and $\mathrm{S} 2$ flow to the grid, output voltage is 0 .

$\mathrm{O} 2$ state: $\mathrm{S} 2$ and $\mathrm{S} 3$ are turned on, $\mathrm{S} 1$ and $\mathrm{S} 4$ are turned off, and the current flows from the grid to the midpoint $\mathrm{O}$ of the
DC voltage through S3 and D2, and the output voltage is 0 .

N1 state: S4 is turned on, S1, S2 and S3 are turned off, and the current flows from the grid to the converter DC side through $\mathrm{S} 4$, and the output voltage is $-0.5 \mathrm{U}_{\mathrm{dc}}$.

$\mathrm{N} 2$ state: S4 is on, S1, S2 and S3 are off, and the current flows from the converter DC side to the grid through D4. The output voltage is $-0.5 \mathrm{U}_{\mathrm{dc}}$.

Based on the analysis above, we know that the output voltage of T-type topology has three levels, i.e. $+0.5 \mathrm{U}_{\mathrm{dc}}, 0$, and $-0.5 \mathrm{U}_{\mathrm{dc}}$. As a result, the voltage stress of the switches and the harmonics of the output current are reduced.

Because the current control of the PCS in a stationary coordinate system follows a sinusoidal AC current, the PI controller cannot be used. Rotating coordinate transformation is usually used to transform the three-phase stationary coordinate system to the synchronous rotating coordinate system. The three-phase AC quantity is converted to the two-phase DC quantity. The PI controller can follow the DC quantity without static error.

For the energy storage PCS with LC filter as shown in the Fig. $1, U_{\mathrm{a}}, U_{\mathrm{b}}, U_{\mathrm{c}}$ denotes the output voltage of the converter, $e_{\mathrm{a}}, e_{\mathrm{b}}$, and $e_{\mathrm{c}}$ are the grid voltage, and $I_{\mathrm{a}}, I_{\mathrm{b}}$, and $I_{\mathrm{c}}$ represent the current flowing through the filter inductor, $L_{\mathrm{a}}, L_{\mathrm{b}}$ and $L_{\mathrm{c}}$ are the inductance of the AC filter inductor, $R_{\mathrm{a}}, R_{\mathrm{b}}$ and $R_{\mathrm{c}}$ are the equivalent resistance of the inductor and the devices in the circuit.

The current is defined as positive when it flows from the grid to the converter. Therefore, when the PCS works in the rectifier mode, the output current of the PCS is in phase with the grid voltage. According to Kirchhoff's voltage law, (1) can be obtained:

$$
\left[\begin{array}{c}
U_{a} \\
U_{b} \\
U_{c}
\end{array}\right]=L p\left[\begin{array}{c}
I_{a} \\
I_{b} \\
I_{c}
\end{array}\right]+R\left[\begin{array}{c}
I_{a} \\
I_{b} \\
I_{c}
\end{array}\right]+\left[\begin{array}{c}
e_{a} \\
e_{b} \\
e_{c}
\end{array}\right] .
$$

In order to adopt PI control in PCS, it is necessary to transform the three-phase AC quantity to the power frequency synchronous rotation coordinate system through coordinate transformation. Equation (2) is a mathematical model in the rotating coordinate system, where $p$ is the differential operator, $U_{\mathrm{d}}$ and $U_{\mathrm{q}}$ are the direct axis voltage and quadrature axis voltage of the control output, $I_{\mathrm{d}}$ and $I_{\mathrm{q}}$ are the straight axis and quadrature axis current, $e_{\mathrm{d}}$ and $e_{\mathrm{q}}$ are the straight axis voltage and quadrature axis voltage of grid voltage, and $R$ is the equivalent resistance of the circuit, $L$ is the output filter inductance of the PCS, $\omega$ is the grid angular frequency:

$$
\left[\begin{array}{l}
U_{d} \\
U_{q}
\end{array}\right]=L p\left[\begin{array}{l}
I_{d} \\
I_{q}
\end{array}\right]-\left[\begin{array}{cc}
0 & \omega L \\
\omega L & 0
\end{array}\right]\left[\begin{array}{l}
I_{d} \\
I_{q}
\end{array}\right]+R\left[\begin{array}{l}
I_{d} \\
I_{q}
\end{array}\right]+\left[\begin{array}{c}
e_{d} \\
e_{q}
\end{array}\right]
$$

In the rotating coordinate system, the direct axis current and the quadrature axis current are coupled with each other and are affected by the grid voltage. Therefore, the feedforward method is used for decoupling.

Equation (3) is the decoupling control equation when the PI controller is used: 


$$
\left\{\begin{array}{l}
U_{\mathrm{d}}=\left(K_{\mathrm{p}}+\frac{K_{\mathrm{i}}}{\mathrm{s}}\right)\left(I_{\mathrm{d}}^{*}-I_{d}\right)-\omega L I_{q}+e_{d}, \\
U_{\mathrm{q}}=\left(K_{\mathrm{p}}+\frac{K_{\mathrm{i}}}{\mathrm{s}}\right)\left(I_{q}^{*}-I_{q}\right)+\omega L I_{d}+e_{q},
\end{array}\right.
$$

where $K_{\mathrm{p}}$ and $K_{\mathrm{i}}$ are the parameters of the PI controller, $I_{\mathrm{d}}{ }^{*}$ and $I_{\mathrm{q}} *$ are the straight axis and quadrature axis reference current.

Figure 3 is the control block diagram of the feedforward decoupling control based on (3). Through the feedforward decoupling control, the control between the direct axis current and the quadrature axis current is completely decoupled.

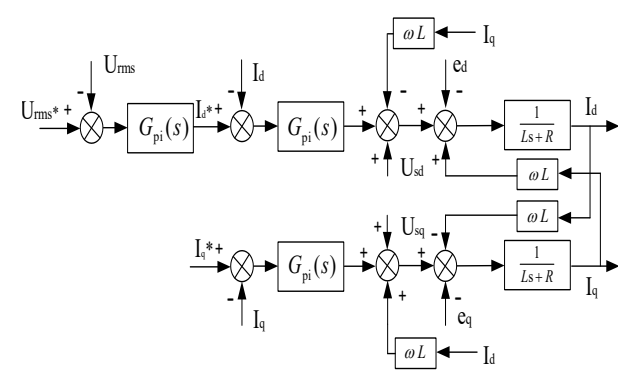

Fig. 3. Block diagram of the feed-forward decoupling control.

\section{HYBRID CONTROL SCHEME}

The output current feedforward decoupling control in the synchronous rotating coordinate system can obtain output current with high quality under grid connection operation. However, the output characteristic of this control method is a current source. Therefore, it cannot guarantee to supply power to the critical local load when PCS works on stand-alone mode.

The output characteristics of the PCS can be changed by adding a voltage loop with the grid voltage RMS. The control block diagram of the feedforward decoupling control after introducing the voltage loop is shown in Fig. 4. The output of the voltage loop is used as the input of the direct axis current loop. By doing so, the external characteristic of the PCS is a voltage source.

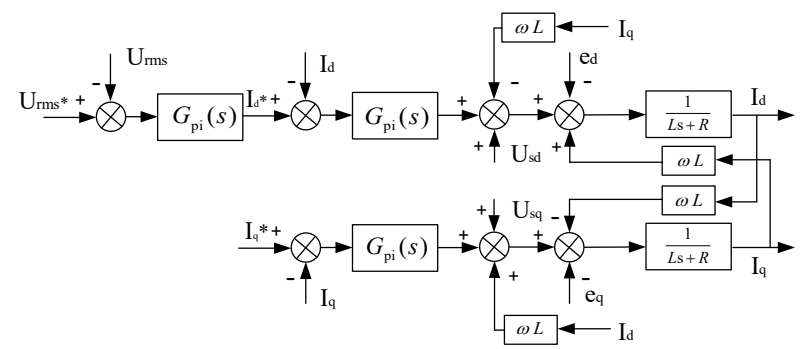

Fig. 4. Block diagram of the feedforward decoupling control with voltage loop.

Due to the limitation of the voltage and current capacity of power electronic devices in applications, the capacity of a single PCS is difficult to meet large-scale energy storage system. It is necessary to combine multiple PCS into a parallel system to extend the system capacity. The output characteristic of each PCS controlled by the scheme of Fig. 4 is a voltage source when PCS work in stand-alone modes, resulting in circulating current in the systems with multiple PCS in parallel. The droop control is for parallel connection operation. It introduces the output droop characteristics of synchronous generator into the control loop of the PCS. The output of PCS follows the given droop characteristic curve to regulate the PCS output frequency and voltage amplitude; thus, suppressing the circulating current among PCS.

In order to make the designed PCS satisfy the different operation modes, including grid-tied, stand-alone, and parallel connection modes, the complete parallel control is designed and depicted in Fig. 5. The different control block or strategies are activated easily by microprocessor by detecting the operation environment. Among them, the block I of PQ control is adopted, when the PCS is connected to the grid. Under this mode, the bidirectional operation of charging or discharging is easily achieved by changing the sign of the active power reference $P^{*}$. The block II of voltage and current double loop control is used when the single PCS is off the grid or stand-alone mode. And the block III of droop control is used to suppress the circulating current among the PCS when the multiple PCS are in parallel operation.

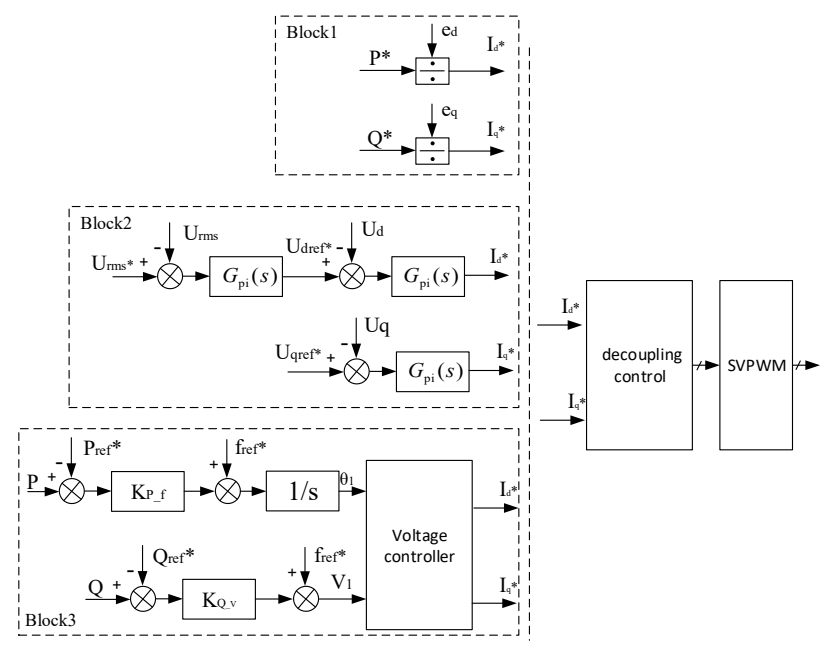

Fig. 5. Block diagram of parallel connection control loop.

\section{PCS Key PARAMETER DESIGN}

The high power PCS prototype parameters are shown in Table I. The DC side is connected to a battery pack with a rated voltage of $720 \mathrm{~V}$, and the AC side is connected to the grid. Since the output RMS current is $721.6 \mathrm{~A}$, the prototype uses the T-type IGBT module 4MBI900VB-120R1-50, which has rated voltage of $1200 \mathrm{~V}$ and rated current of $900 \mathrm{~A}$. Considering the overload operation of PCS, the selection of switch needs to leave a certain margin, and each phase uses two IGBT modules in parallel.

TABLE I. 500 KW PCS DESIGN PARAMETERS.

\begin{tabular}{|c|c|}
\hline Parameters & Value \\
\hline Grid line voltage & $400 \mathrm{Vac} \pm 15 \%$ \\
\hline DC side voltage & $600 \mathrm{~V}-900 \mathrm{~V} /$ Rated $720 \mathrm{~V}$ \\
\hline PCS power & $500 \mathrm{~kW}$ \\
\hline Rated Output AC current & $721.6 \mathrm{~A}$ \\
\hline Switching frequency & $3 \mathrm{kHz}$ \\
\hline Efficiency & $>98 \%$ \\
\hline AC current THD & $<5 \%$ \\
\hline
\end{tabular}

A filter is used on the AC side to filter high-frequency 
switching ripple. The filter inductor $L$ is determined by the current ripple value. And it should be balanced between inductor size and efficiency, current THD. In this design, the inductor current ripple is designed with $20 \%$ of the rated current. It can be calculated according to the empirical formula of (4), where $U_{\mathrm{DC}}$ is the DC side voltage, $T_{\mathrm{s}}$ is the switching period, and $\Delta I_{\mathrm{L}}$ is the inductor current ripple, the designed filter inductor is $100 \mathrm{uH}$

$$
L \geq \frac{U_{D C} T_{s}}{6 \Delta I_{L}} .
$$

The design of the filter capacitor $\mathrm{C}$ mainly considers the reduction of the PCS output power factor caused by the capacitor. The reactive power caused by the capacitor should be less than $5 \%$ of the rated power. Equation (5) is the empirical formula of the filter capacitor when the reactive power is determined, where $P_{\mathrm{n}}$ is the rated output power of the PCS, the designed each phase capacitor is $100 \mathrm{uF}$

$$
C=\frac{P_{\mathrm{n}} / 3}{2 \pi f_{\text {grid }} U_{d c}^{2}} 0.05
$$

The DC bus capacitor is mainly used to buffer the energy between the DC side battery and the load, and to stabilize the DC side voltage. The capacitor design of the DC bus mainly considers stability of the DC side voltage when the load changes suddenly. Considering the response to the load sudden change, the DC side voltage fluctuates less than $5 \%$. The calculation formula of the DC side capacitor is shown in (6), where $R_{\mathrm{Le}}$ is the Rated DC load resistance, $I_{\mathrm{m}}$ is the maximum DC side current when considering overload and the designed DC side capacitance is $15 \mathrm{mF}$

$$
C_{D C}=\frac{U_{d c}{ }^{2}}{2 \Delta U_{d c} I_{\mathrm{m}} R_{\mathrm{Le}}} .
$$

Comparing with the two-level topology PCS, the T-type three-level topology has a larger number of switches and the SVPWM modulation method is more complicated. Therefore, it is necessary to use a DSP and an FPGA processor to implement it. The design uses DSP chip TMS320F28335 and FPGA chip to cooperate with each other for control. The DSP processor is responsible for sampling, the control calculation, and the system protection, etc., while the FPGA processor is responsible for producing the driving signal for the switches according to the control output.

\section{EXPERIMENTS}

Based on the design parameters, a $500 \mathrm{~kW}$ prototype was built to verify the control strategy and the design. The experiment test platform is shown in Fig. 6. The DC side voltage of the PCS is provided by a three-phase PWM rectifier supplied by the grid, and the $\mathrm{AC}$ side is connected to the utility power grid through an AC contactor. Local critical resistive loads are connected in parallel with the AC bus. In the discharge experiment, the PWM rectifier transfers power from the grid to the DC side of the PCS, and then the PCS inverts DC power back to the grid. The power flow of the charging experiment is in opposite.

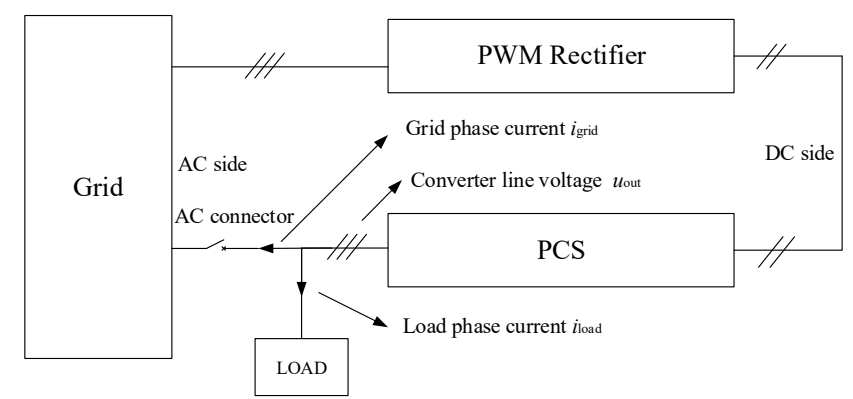

Fig. 6. Grid-tied mode experiments platform.

Figure 7 shows the voltage and current waveforms of the full load charge and discharge switching waveform. Channel 1 is a DC voltage waveform $u_{\text {dc }}$. Channel 2 is the $u_{\text {grid }}$ of grid line voltage. Channel 3 is the grid connection phase current $i_{\text {grid, }}$ Charge and discharge switching is achieved by linearly changing the active power reference. As shown in Fig. 7, the switching time is about $140 \mathrm{~ms}$, and the switching process is smooth.

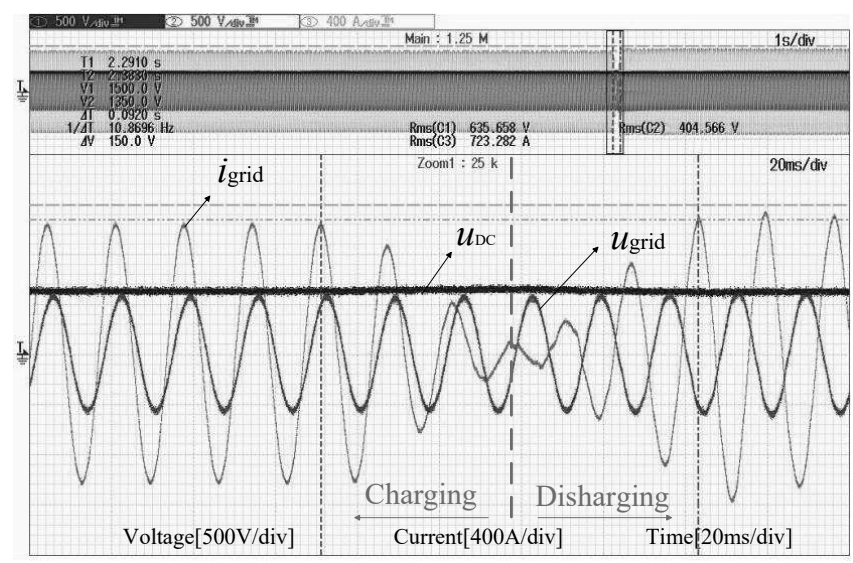

Fig. 7. Full load charge and discharge switching waveform.

Figure 8 shows the voltage and current waveforms of the switch transition from grid-tied mode to stand-alone mode. Channel 1 is the control signal $u_{\text {control }}$ of the AC contactor from the DSP.

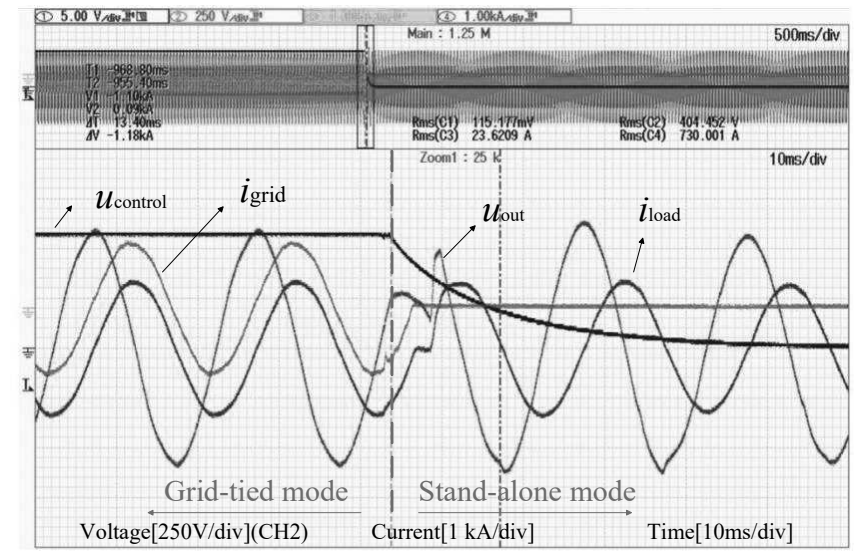

Fig. 8. Voltage and current waveforms in switch transition from grid-tied mode to stand-alone mode.

Channel 2 is the output line voltage $u_{\text {out }}$ of the converter. Channel 3 is the grid connection phase current $i_{\text {grid, }}$, and Channel 4 is the load phase current $i_{\text {load }}$. It shows that when the 
off-grid signal $u_{\text {control }}$ arrives to turn off the AC contactor, the PCS voltage control loop is activated quickly, i.g. $i_{\text {grid }}=0$, and $i_{\mathrm{PCS}}=i_{\text {load }}$. The PCS operates under stand-alone mode and reach steady state after about half-cycle adjustment.

Figure 9 shows the voltage and current waveforms of the switch transition from stand-alone mode to grid-tied mode. When the AC contactor is turned on by the signal $u_{\text {control, }}$, the processor firstly samples the voltage and current to determine whether the grid-connected condition is satisfied. If the grid-connected condition is satisfied, PCS begins to deliver energy to the grid, i.g. $i_{\mathrm{PCS}}=i_{\text {grid }}+i_{\text {load }}$. As can be seen from Fig. 9, the load current has small distortion and high quality during the whole switch transition, and the transition is smooth.

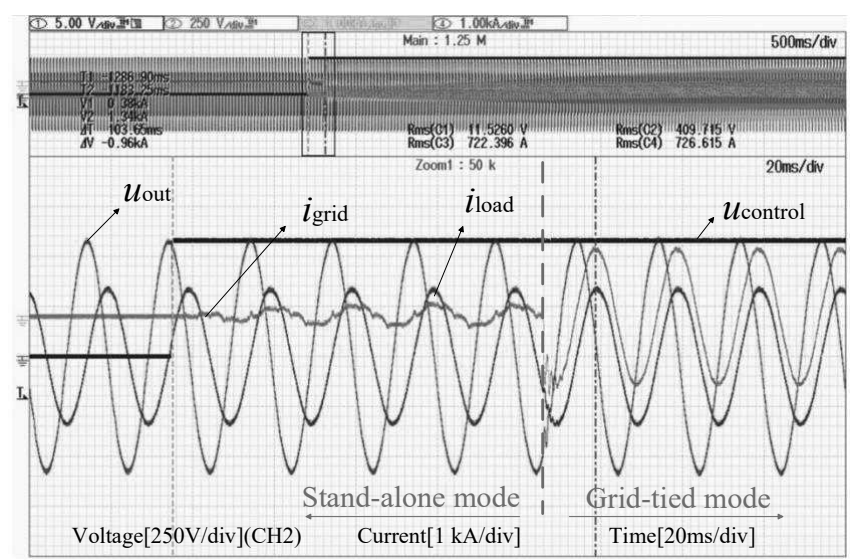

Fig. 9. Voltage and current waveforms in switch transition from stand-alone mode to grid-tied mode.

The multiple PCS parallel connection operation experiment platform is shown in Fig. 10, where the DC voltage is provided by a three-phase PWM rectifier, and the multiple PCS parallel system is consisted by two $500 \mathrm{~kW}$ energy storage PCS connected in parallel. The load is $186 \mathrm{~kW}$ resistive load.

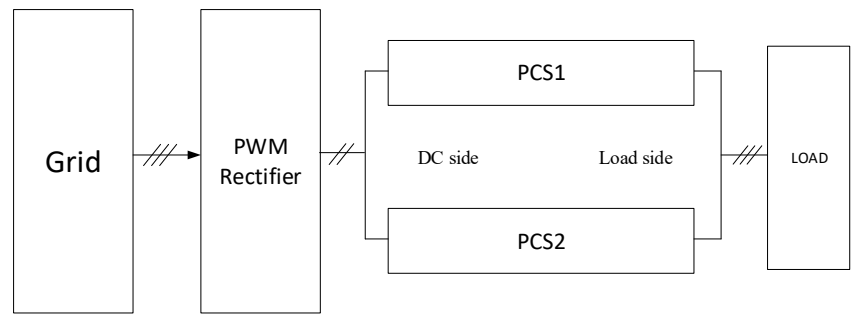

Fig. 10. Stand-alone mode of multiple PCS parallel experiment platform.

Figure 11 is voltage and current waveform under with load and with load step change from load to no load in a multiple PCS parallel system. Channel 1 is the output voltage $u_{\text {load }}$ of PCS, Channel 3 is the output current $i_{\mathrm{PCS} 1}$ of PCS1, and Channel 4 is the output current $i_{\mathrm{PCS} 2}$ of PCS2. It can be seen that there is good current sharing and the circulating current under no-load is about $4.5 \mathrm{~A}$, which verifies effective suppression on circulating current of the control method.

Figure 12 is the efficiency curve of the PCS prototype. The charge and discharge mode tests are performed at the rated battery voltage of $720 \mathrm{~V}$ and the rated grid voltage of 400 Vac.

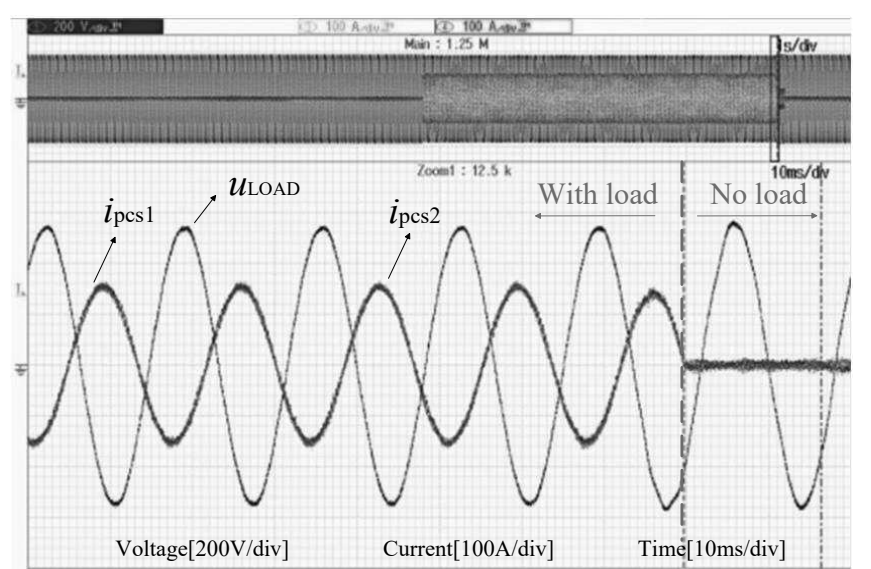

Fig. 11. Voltage and current waveforms in multiple PCS parallel connection operation mode.

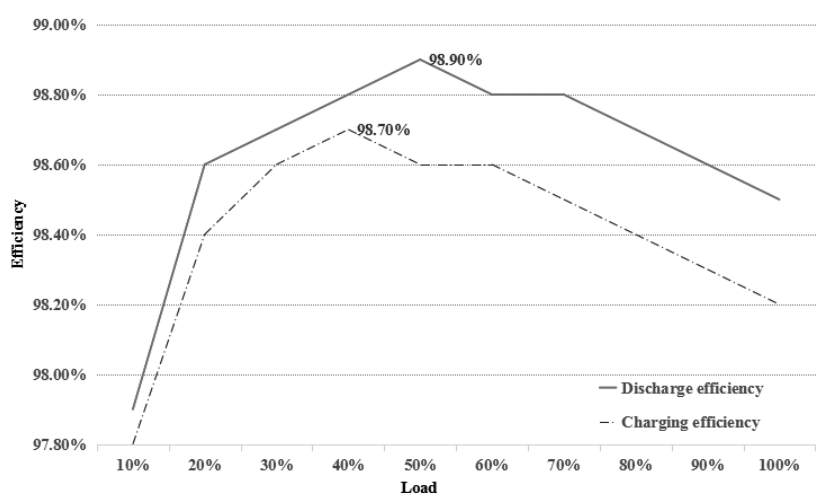

Fig. 12. $500 \mathrm{~kW}$ PCS prototype charge and discharge efficiency.

It can be seen from the above experiments that the multiple PCSs parallel system works stably, and has low THD grid-tied current with about $3 \%$ under full load, good current sharing with the circulating current of 4.5 A under no-load. The prototype efficiency is above $98 \%$ under most of output power and reach $98.9 \%$ peak efficiency.

\section{CONCLUSIONS}

The PCS has great effect on the energy system working stability and power quality, and it will be challenged by complicated operation modes, including grid-tied mode, stand-alone mode, and parallel connection mode. Single control cannot meet the operation challenges. The hybrid control scheme is proposed for the high-power PCS.

In the hybrid control scheme consisted with three block controls, PQ control is adopted when the PCS is connected to the grid; voltage and current double loop control is used when the single PCS is off the grid, and the droop control is used to suppress the circulating current among the PCS when the multiple PCS are in parallel operation. The different control strategies are activated easily by microprocessor by detecting the operation conditions.

A $500 \mathrm{~kW}$ T-type three-level energy storage PCS prototype is built to verify the design and control. The PCS prototype has good steady and dynamic performance, which has grid-tied current with THD of $3 \%$ at full load, peak efficiency of $98.9 \%$, and low circulating current of $4.5 \mathrm{~A}$ in parallel operation under no load. The experimental results show that the hybrid control strategy proposed in this paper can meet the 
different operation modes, including grid-tied, stand-alone, and parallel modes.

\section{REFERENCES}

[1] J. M. Crider, S. D. Sudhoff, "Reducing impact of pulsed power loads on microgrid power systems", IEEE Trans. Smart Grid, vol. 1, no. 3, pp. 270-277, 2010. DOI: 10.1109/TSG.2010.2080329.

[2] M. Farhadi, O. A. Mohammed, "Real-time operation and harmonic analysis of isolated and non-isolated hybrid DC microgrid", IEEE Trans. Industry Applications, vol. 50, no. 4, pp. 2900-2909, 2014. DOI: 10.1109/TIA.2014.2298556.

[3] C. Abbey, G. Joos, "Supercapacitor energy storage for wind energy applications", IEEE Trans. Industry Applications, vol. 43, no. 3, pp. 769-776, 2007. DOI: 10.1109/TIA.2007.895768.

[4] G. Cimuca, S. Breban, M. M. Radulescu, C. Saudemont, B. Robyns, "Design and control strategies of an induction-machine-based flywheel energy storage system associated to a variable-speed wind generator", IEEE Trans. Energy Conversion, vol. 25, no. 2, pp. 526-534, 2010. DOI: 10.1109/TEC.2010.2045925.

[5] R. Arghandeh, M. Pipattanasomporn, S. Rahman, "Flywheel energy storage systems for ride-through applications in a facility microgrid", IEEE Trans. Smart Grid, vol. 3, no. 4, pp. 1955-1962, 2012. DOI: 10.1109/TSG.2012.2212468

[6] M. P. Aguirre, L. Calvino, M. I. Valla, "Multilevel current-source inverter with FPGA control", IEEE Trans. Industrial Electronics, vol. 60, no. 1, pp. 3-10, 2013. DOI: 10.1109/TIE.2012.2185014.

[7] X. Guo, Y. Bai, B. Wang, "A programmable single-phase multilevel current source inverter", IEEE Access, vol. 7, pp. 102417-102426, 2019. DOI: 10.1109/ACCESS.2019.2931741.
[8] X. Meng, J. Liu, Z. Liu, “A generalized droop control for grid-supporting inverter based on comparison between traditional droop control and virtual synchronous generator control", IEEE Trans. Power Electronics, vol. 34, no. 6, pp. 5416-5438, 2019. DOI: 10.1109/TPEL.2018.2868722.

[9] D. Mukherjee, D. Kastha, "Voltage sensorless control of VIENNA rectifier in the input current oriented reference frame", IEEE Trans. Power Electronics, vol. 34, no. 8, pp. 8079-8091, 2019. DOI: 10.1109/TPEL.2018.2878680.

[10] Y. Sun, X. Hou, J. Yang, H. Han, M. Su, J. M. Guerrero, "New perspectives on droop control in AC microgrid", IEEE Trans. Industrial Electronics, vol. 64, no. 7, pp. 5741-5745, 2017. DOI: 10.1109/TIE.2017.2677328.

[11] S. Oncu, H. Ozbay, "Simulink model of parallel resonant inverter with DSP based PLL controller", Elektronika ir Elektrotechnika, vol. 21, no. 6, pp. 14-17, 2015. DOI: 10.5755/j01.eee.21.6.13751.

[12] M. Pastor, J. Dudrik, "Design of output LCL filter for 15-level cascade inverter", Elektronika ir Elektrotechnika, vol. 19, no. 8, pp. 45-48, 2013. DOI: $10.5755 /$ j01.eee. 19.8 .5394 .

[13] H. Heydari, A. H. Moghadasi, "Optimization scheme in combinatorial UPQC and SFCL using normalized simulated annealing", IEEE Trans. Power Delivery, vol. 26, no. 3, pp. 1489-1498, 2011. DOI: 10.1109/TPWRD.2011.2111390.

[14] J. Zakis, E. Makovenko, H. Zeng, "qZS inverter as synchronverter in small-scale micro-Grid", Elektronika ir Elektrotechnika, vol. 24, no. 2, pp. 58-62, 2018. DOI: 10.5755/j01.eie.24.2.20636.

[15] H. Kanchev, N. Hinov, B. Gilev, and B. Francois, "Modelling and Control by Neural Network of Electric Vehicle Traction System", Elektronika ir Elektrotechnika, vol. 24, no. 3, pp. 23-28, 2018. DOI: 10.5755/j01.eie.24.3.20974. 